\title{
A Complete Review on 3d Printing and Different Process Parameters on which it's Performance Depends
}

\author{
Santosh Kumar Patel, Dinesh Kumar Soni
}

\begin{abstract}
D printing is the most advance method of additive manufacturing. In this process, component is made by directly depositing one layer above another. $3 D$ printing has unique ability to produce direct end product which can be directly used without any further process. It can print highly complex design product which are not possible through conventional method of manufacturing. Additive manufacturing has wide area of application like medical, heat transfer, mechanical and many more. Since last two decades, there is a drastic change in the research of additive manufacturing. Researcher are optimizing the different process parameters which make $3 D$ printing more valuable and flexible so that it can fulfill the requirement of different areas of application. So it is necessary to understand the different process parameters and mechanism which are responsible for high quality $3 D$ printing. Here in this paper a complete review of $3 D$ printing is done.
\end{abstract}

Keywords- 3D printing, parameters, process, methods, review

\section{INTRODUCTION}

In order to compete in the current global business environment, it is necessary that the industrialization process has to be effective and efficient. The current market demand is to develop rapid product without wasting the material and time, it also needed to have lots of flexibilities in terms of design and manufacturing. To achieve this, the production system and product development process must be synchronized, and their interaction seamless. Previously many of the conventional methods were used to develop or manufacture end products which required lot of pre and post processes to develop product. So in order to eliminate the deficiency of conventional manufacturing people start using of additive manufacturing. In the 20th century, revolution for the industrialization process and product development is the main concerned. Because of this people are mainly focusing on Computer Aided Engineering (CAE), and Computer Aided Design (CAD). By using these software, Ford Motor Company cut the time to market by a third [1, 2]. The use of Additive Manufacturing (AM) technologies which made it possible to produce parts and components of end use products based on CAD drawings, was a recent trend for the industries [3].

Revised Manuscript Received on August 15, 2020.

*Correspondence Author

Santosh Kumar Patel1*, S. V. Polytechnic College, Kamla Park Rd, Krishna Nagar, Shymala Hills, Bhopal, Madhya Pradesh

Dinesh Kumar Soni, Rabindranath Tagore University, Mendua, Post Bhojpur, Near Bangrasiya Chouraha, Bhopal-Chiklod Road, Raisen, Madhya Pradesh, India.

(C) The Authors. Published by Blue Eyes Intelligence Engineering and Sciences Publication (BEIESP). This is an open access article under the CC BY-NC-ND license (http://creativecommons.org/licenses/by-nc-nd/4.0/)
Through additive manufacturing complex products to be manufactured in practically, even most complex shape in three dimensions can also be made. AM uses layer-by-layer technique, which makes it possible to print and manufacture parts and details without involving other complex and traditional manufacturing processes. The key advantage of using AM is the simplicity of printing out functional parts designed in CAD and simple objects are printed in less than one hour [4, 5]. The application of AM in different industries has rapidly increased during recent years. Boparai et al. [4] present a percentage utilization of the use of AM in different industries, presented in figure 1 . The automotive business is among those that utilize this new technology the most.

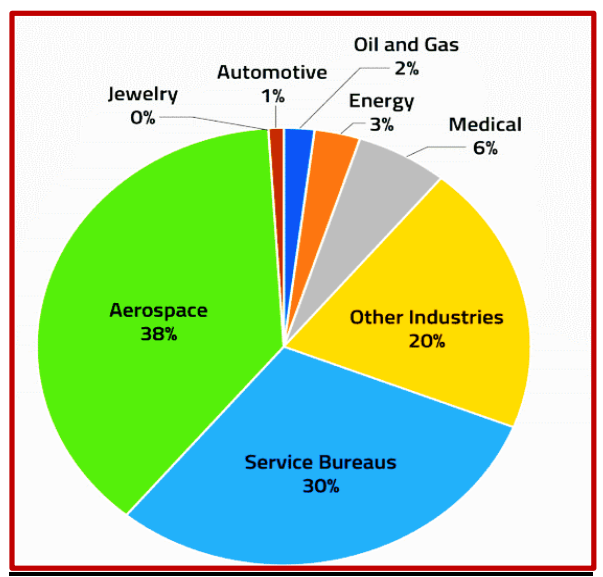

Figure 1. The Use of AM in Various Industries [6]

In 1981, municipal industrial research institute situated in Nagoya developed a functional rapid prototyping method or system for photopolymer (Autodesk 2014). In 1984 steriolithographic was introduced by Charles Hull where as in 1992 worlds first stereolithographic instrument was introduced in to the market. The main purpose of 3D printing invention at the early age when Charles hull developed is to develop prototypes of actual product directly from computer aided design. It is mainly developed to help designer and engineer to test their ideas without going for the actual test analysis. With the help of $3 \mathrm{D}$ printing designer and engineer can test the feasibility of their ideas and also identify the different process parameters on which the performance of end product mainly depends. Charles Hull invention had save the huge amount of money and time that was invested on developing new products to full fill the market demand. Additive manufacturing (3D printing) is a method to produced direct end product through layer by layer deposition of material one above another.

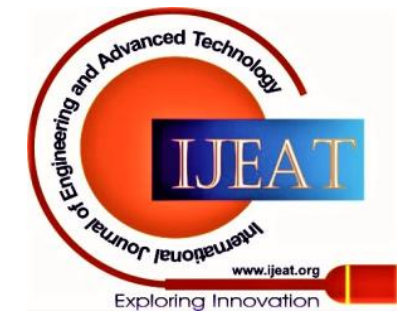


Different additive manufacturing technique covers all range of materials like metal, plastic, ceramic and bio-medical, it includes all field of materials to manufacture different products applicable in different areas. Different complicated geometries which are very difficult to manufacture with the help of conventional method can easily manufacture with the help of additive manufacturing. By using 3D scanners and CAD software's, 3D model of product gets easily available. Using tessellation software, 3D model gets sliced in to different numbers of layers, which help in building 3D printed components. 3D printing are classified in to different set of processes. Fig.2 shows the different methods and process of 3D printing of additive manufacturing.

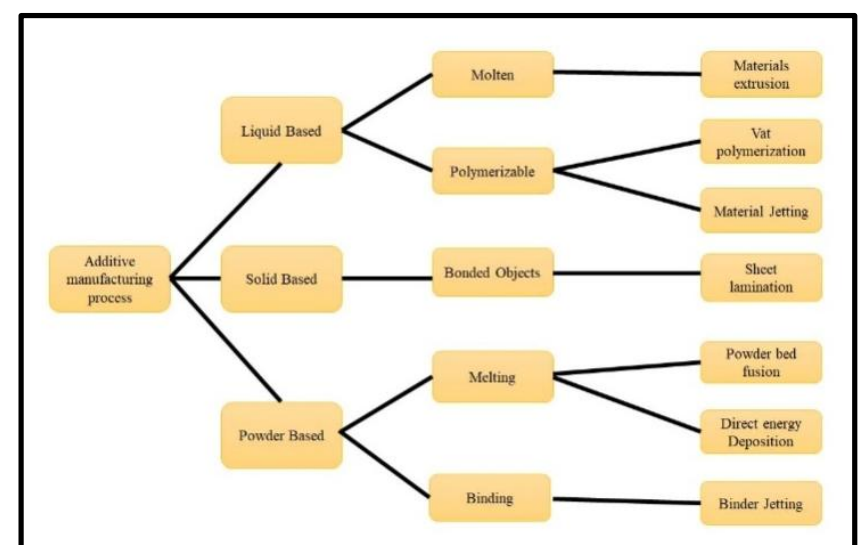

Figure 2. Shows the classification of additive manufacturing processes

\section{STEPS INVOLVE IN ADDITIVE MANUFACTURING}

For manufacturing the 3D printed components manly three steps involve in that that are geometric modelling, tessellation of geometric model and slicing. In geometric modelling, creation of CAD file of the component was made. With the help of the CAD file tessellation of geometric model will be done. During tessellation, the CAD model was converted in to the STL file which is the standard format file for $3 \mathrm{D}$ printing. During tessellation, the surface of the CDA model is converted into a surface made by number of triangles arranged to distinguish the interior from the exterior surface of the model. During slicing, STL file get sliced in to number of horizontal layers which are closely packed to each other. In 3D printing, the horizontal layer formed in to $\mathrm{x}-\mathrm{y}$ direction while the layering occurs in the z-direction. Subsequent layers were deposited one above the another and form final components through additive manufacturing. In last decade, 3D printing has attracted the interest of researcher and manufacturer because of their feasibility and flexibility in manufacturing of components. 3D printing process are mainly classified in to seven different categories that are powder bed fusion process, sheet lamination, material extrusion through nozzle, powder jetting, direct energy deposition and binder jetting. Many of the researchers and academician have identified the different process parameters and mechanism on which the performance of 3D printing depends. Kampkera et.al [7] they classified the framework of system on the basis of material extrusion in additive manufacturing process. They develop the systematic approach and identifies the different numbers of moments on the basis of which the material extrusion printer system must be classified. Li et.al [8] they investigates the different design and process parameters of fused deposition modelling technique which is mainly used for low-melting metal alloy. They mainly focus to optimized the different parameters and to reduce the time and cost of the manufacturing process. In order to achieve the set goals, they first set the scheme for the overall structural design of the component. In the second phase, they design the key part FDM process that is structure of extrusion system. Zhang et.al [9] they investigate the printing quality and blockage inside the nozzle where color mixing is happening in fused deposition modelling (FDM). They used vibration test method to study the feed parameters of FDM process of 3DF printing. They conduct the actual testing for ABS material and found that the optimum feed speed in 2 $\mathrm{mm} / \mathrm{min}$. Moetazedian et.al [10] here they had developed the novel design to check the anisotropic mechanical behavior of specimen manufactured through additive manufacturing during tensile testing. They had considered the three different environmental factors that are hydration (where samples were placed in solution for $48 \mathrm{hr}$ ), in-aqua testing (samples where submerged in to the solution during testing) and physiological temperature that is $37^{\circ} \mathrm{C}$. Through experiment, it was found that the tensile strength of the hydrated samples test conducted under submerge condition was reduced to $49.99 \%$, whereas the elastic modulus was reduced by $20.3 \%$. Armillotta et.al [11] the main objectives of the work is to identify the effect of different geometric process parameters on defects that can be generated during manufacturing of blocked shape part of ABS thermoplastic resin. The geometric functional parameters that are considered to detect defect are the size of the part in three dimensional and the later thickness of deposition. To measure the defect as a variable of these two parameters, different set of combinations of these two parameters were conducted experimentally. After manufacturing the specimen with different combinations geometric deviation in each case was measured and analyzed. through this process they identifies the parameter which is influencing more as compare to other on product during manufacturing. Cantrell et.al [12] a comprehensive effort has been undertaken to determine the mechanical properties of 3D printed Polylactic Acid (PLA) for use in finite element analysis (FEA). The mechanical properties of 3D printed parts are dependent on the processing parameters used. The effects of temperature, layer thickness, infill direction and speed are investigated to determine the effects of each parameter on the mechanical properties of a printed part. Blok et.al [13] they analyzed the effect of reinforcing the nylon fiber with carbon fiber through mechanical testing and optical microscopy. For printing the reinforced carbon fibernylon composite fibers they used markOne 3D printer and used to print of filament of $0.1 \mathrm{~mm}$ size. Through experiment it is found that the reinforcing the nylon fibers with carbon fiber shows the significant improvement in mechanical properties over unreinforced epoxy matrix.

Published By:

Blue Eyes Intelligence Engineering DOI: 10.35940/ijeat.F1366.089620

Journal Website: www.ijeat.org and Sciences Publication

(C) Copyright: All rights reserved. 
Sakin et.al [14] the developed the technology to build sustainable houses for future through additive manufacturing. Different technologies that are used to build or to construct buildings are describe in this paper. With the use of these methods or technologies, construction of building can get the revolution in construction sector.

\section{EFFECT OF MATERIAL DEPOSITION ORIENTATION ON ADDITIVE MANUFACTURING}

Ga et.al [15] they presented a methodology in additive manufacturing to position a part building. This methodology handles several conditions which are necessary for good additive manufacturing product like surface quality, volume of support and cost. The end objective of this methodology is to reduce these criteria. In order to check the feasibility of this methodology, it is applied to several industrial cases to measure the accuracy level. Through evaluation it is found that weight values play an important role in part building orientation. Das et.al [16] they developed an approach to identify the optimum building orientation to minimize volume support structure with meeting the required geometric dimensioning and tolerancing. With the help of siemens PLM NX API geometric dimensioning and tolerancing data was extracted and associated with the CAD model. Through combination of mathematical relationship in between different parameters to find best building orientation. Delfs et.al [17] they aim to predict the surface quality of the $3 \mathrm{D}$ printed components which depends on the material deposition orientation. They developed the model which uses the digital AMF format in which every triangle was assigned with a certain value of roughness. Testing of different specimen with different orientation was done to find best one. In order to validate the model it uses a monitor bracket of EOS GmbH. Huang et.al [18] they proposed a new method to find the optimum part material deposition orientation for additive manufacturing mainly for fused deposition modelling. In this model they mainly considered two objectives which works both at a time that is feature roughness and build time. The results show that the used of this model reduces the running time by $94.8 \%$ as compared to traditional method. Langelaar [19] they develop the numerical model to optimize part geometry, orientation of material deposition and support layout. With the help of this model, designers are allowing to find the rational balance in between manufacturing cost and manufactured part performance. The computational cost of this model is very less, whereas the solution quality is very high. Moroni et.al [20] in this work they develop the model which considered complete part under consideration which means they include all the parameters which play an role in building the 3D components. In order to check the feasibility of the model, this work includes the complete study of U-joint manufactured through 3D printing. Pereira et.al [21] they develop some mathematical relations which are able to find the limitations that can come during orientation of model, slicing and support. During manufacturing of 3D printed components slicing is the main concern, because during slicing the main difficult that people face is staircase effect. This condition become more critical in case of objects having slopes and curvatures

Published By

Blue Eyes Intelligence Engineering and Sciences Publication

(C) Copyright: All rights reserved.

which results in high roughness on the surface of printed component. Zhang et.al [22] they introduce the two step method, in order to find the optimum conditions during manufacturing of multiple products at a time. Firstly, they developed the feature based model which is mainly used to developed the optimal building condition to print multiple products at a time. In order to optimize the conditions, first they print the components with different orientation and optimize the different parameters to reduce the build time and achieve high surface quality. In this work they print 16 parts simultaneously with in a given chamber of 3D printer.

\section{EFFECT OF NOZZLE PARAMETERS ON ADDITIVE MANUFACTURING}

In additive manufacturing nozzle different parameters like nozzle angle, nozzle diameter and temperature play a very important role during manufacturing. Nozzle angle affect the feed rate and pressure applied inside the nozzle to extrude the material, whereas nozzle diameters is directly related with the surface finishing and build time of the component. Many of the researchers had done the study to investigate different mechanism which is directly related with the nozzle in 3D printing specially in fused deposition modelling type method. Biedermann et.al [23] they develop the computational design frame work in order to manufacture complex shape geometry using multi-nozzle flow. In this frame work they provide a toolbox which enable user to build finished 3D printed component. Hierarchical architecture organization of elements and implementation was done using object oriented programming. With the modification and used of this frame work any non-expertise person can also build the component very easily. Blake et.al [24] they analyzed the effect of nozzle geometry and extrudarte swell of extruded polymer on their building orientation through computational method. With the help of computational method they evaluate the strokes flow in fused deposition modelling process having axisymmetric flow field. During component building different tensors were calculated using orthotropic fitted closure and isotropic fiber interaction model. Through result it is found that nozzle geometry and extrudate swell can moderately affect the extruded polymer in 3D printing. Nienhaus et.al [25] they investigate the different forces that are acting during extrusion of polymer through nozzle. They analyze the effect of different nozzle parameters on the forces. By fixing the entry and diameter of capillary, effect of change in conical section of nozzle and length of capillary tube on different forces was analyzed through experiment using polylactic acid (PLA) as a working polymer. Through result it is found that with the increase in filament feed velocity, the extrusion forces rise linearly. It was also found that with $56^{\circ}$ conical section the extrusion force is lowest as compared to other conical angle. The test stands used for experimental analysis is shown in the below figure 3.

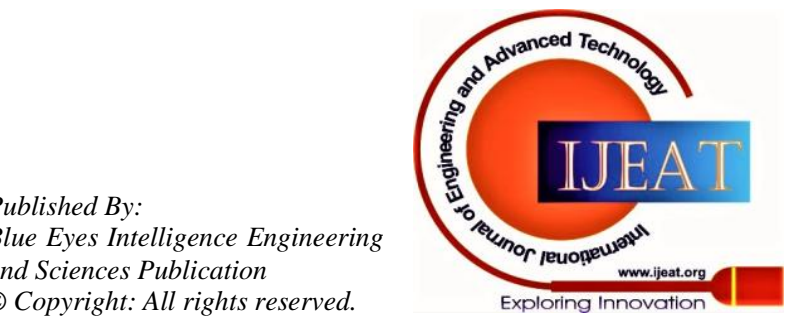




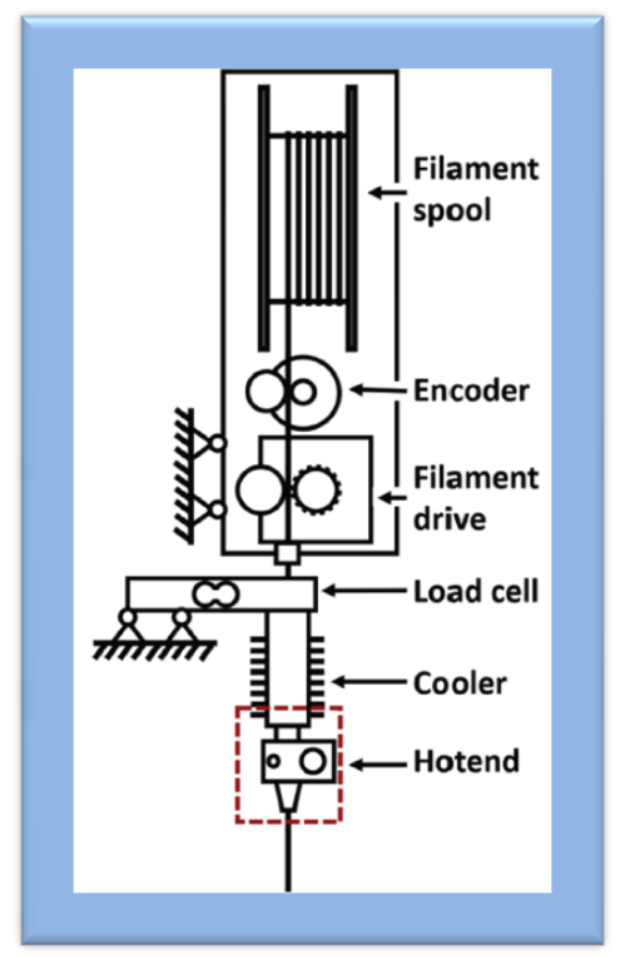

Figure. 3 shows the test stand used for experimental analysis

\section{MISCELLANEOUS PARAMETERS OPTIMIZATION}

Many other parameters are also responsible for getting good quality 3D printing components. Since last two decades, researchers and academician are optimizing the different process parameters to enhance the quality of 3D printing and also trying to make more flexible and easy use. Guo et.al [26] they investigates the different process parameters, materials and different application of additive manufacturing process. They also find the gap where researchers needs to do more research in additive manufacturing to fulfill the requirements of future need. Additive manufacturing was introduced more than 20 years ego, in additive manufacturing rather than removing the material like in conventional manufacturing processes it deposites material layers one above another and build the component. With the help of this manufacturing technique complex shape geometry can be easily manufactured. Suwanprateeb et.al [27] they analyzed the effect of changing the printing parameters of printer which is use to transform plater of paris in to hydroxyapatite through low temperature phosphorization. To analyzed the effect of different powder layer thickness three different layer thickness was considered during the manufacturing of specimen with saturation ratio of 1 and 2 . In oder to analyzed the effect $t$ of these parameters, different properties like microstructure, density, mechanical properties were analyzed for each set of experiment. Through results it is found that these parameters strongly affect the transformation and properties of printed samples. Paul et.al [28] they develop the mathematical model to analyzed the energy requirement of SLS process for the manufacturing of product. The total energy required for the system can be calculated as a total area going to sintered through convex hull based approach. It is also correlated with the different parameters like layer thickness, material deposition orientation and sample geometry. Through this model they calculate the optimum minimum total area sintering and energy required for printing. Kumar et.al [29] they mainly focus on how additive manufacturing help in making patterns for investment casting. Different approaches that is direct and indirect for making pattern was discuss in this work. They also discuss the different process parameters which play an important role during pattern manufacturing through 3D printers. Effect of process parameters like raster angle, road width, built time, part build orientation and air gap on 3D printed product was also reviewed. Chang et al. [30] they develop the method which co related the extruding parameters with the profile error for a sample based on 2D spiral. They proposed a thin 2D-spiral model which had 19 cylinders on the model to evaluate the profile error. With the help of taguchi they optimize the different parameters which are considered during manufacturing of 3D printing. They includes contour width, depth, raster width and raster angle during optimization of parameters. Brajlih et.al [31] they develop the method to compare different machines on the basis of speed and their accuracy. Previous work had already shown that the machine yield can directly affect the achievable speed of 3D printing. Through this method they have categories the different achievable speed for different individual testing machines. Nikzad et.al [32] they investigated, the thermal and mechanical behavior of the newly developed composite material with iron or copper up to $40 \%$ in Acrylonitrile Butadiene Styrene (ABS) was subjected under the earlier existing FDM3000 machinery. This new developed ABS successfully produced and showed more stiffness than other available material and depicted withstanding against higher injection molding pressures. Also thermal and dynamic properties of newly developed ABS with varying metal particle had shown promises for newer applications in functional part of fused deposition modeling. Bakar et.al [33] they investigate the different process parameters of fused deposition modelling prodigy plus. The perform the different experiment and proposed the optimum parameters. To identify the quality of the printed component, they mainly focus on the dimension accuracy and surface finishing of printed component. After optimizing the process parameters, it is then applied to fabricate the mater piece of pattern before making the silicon moulding. With the optimum parameters, it reduces the post processing processes, in order to measure the surface roughness they uses surface roughness tester and coordinate measuring machine for dimension accuracy. Through this study the quality of the produced part get improved mainly in terms of surface roughness and dimension accuracy. Galantucci et.al [34] they study the different process parameters of FDM process in which ABS material is used. The optimum condition was applied to manufacture product through FED process. For post processing through chemical method does not required any human intervention and play an important role to improve the surface quality of the printed component.

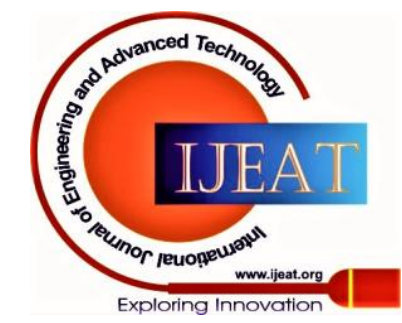




\section{CONCLUSION}

Additive manufacturing is the most advance mode of manufacturing though which final product can be achieved. For obtaining good surface finishing and fine product optimization of feed rate, building orientation angle, material melt temperature should be properly take care. In case of polymer mainly, fused deposition modelling technique is used. Different materials have different process parameters that should be optimize before making component. In SLM or metal additive manufacturing process, many other process parameters like power bet thickness, laser intensity and many other parameters should be optimized. Additive manufacturing have wide scope for researchers to manufacture new end products that are very complicated to build through conventional processes.

\section{REFERENCES}

1. C.K. Chua, M. Vadakke Matham, Y.-J. Kim, Lasers in 3D printing and manufacturing, World Scientific, 2017.

2. J. Bukchin, E. Darel, J. Rubinovitz, International Journal of Production Economics, 51 (1997) 47-57.

3. B. Lyons, The Bridge, 44 (2014) 13-19.

4. K.S. Boparai, R. Singh, H. Singh, Rapid Prototyping Journal, (2016).

5. K.S. Boparai, R. Singh, Development of Rapid Tooling Using Fused Deposition Modeling, Additive Manufacturing of Emerging Materials, Springer, 2019, pp. 251-277.

6. M.B. Mawale, A.M. Kuthe, S.W. Dahake, Concurrent Engineering, 24 (2016) 94-102.

7. A. Kampker, J. Triebs, S. Kawollek, P. Ayvaz, S. Hohenstein, Procedia CIRP, 81 (2019) 815-819.

8. Z. Li, D. Zhang, L. Shao, S. Han, Advances in Mechanical Engineering, 11 (2019) 1687814019896196.

9. B. Li, J. Liu, H. Gu, J. Jiang, J. Zhang, J. Yang, IOP Conference Series: Materials Science and Engineering, IOP Publishing, 2019, pp. 012141.

10. A. Moetazedian, A. Gleadall, X. Han, V.V. Silberschmidt, Journal of the Mechanical Behavior of Biomedical Materials, 102 (2020) 103510.

11. A. Armillotta, M. Bellotti, M. Cavallaro, Robotics and ComputerIntegrated Manufacturing, 50 (2018) 140-152.

12. J.T. Cantrell, S. Rohde, D. Damiani, R. Gurnani, L. DiSandro, J. Anton, A. Young, A. Jerez, D. Steinbach, C. Kroese, Rapid Prototyping Journal, (2017).

13. L.G. Blok, M.L. Longana, H. Yu, B.K. Woods, Additive Manufacturing, 22 (2018) 176-186.

14. M. Sakin, Y.C. Kiroglu, Energy Procedia, 134 (2017) 702-711.

15. B. Ga, N. Gardan, G. Wahu, Computer-Aided Design \& Applications, 16 (2019).

16. P. Das, R. Chandran, R. Samant, S. Anand, Procedia Manufacturing, 1 (2015) 343-354.

17. P. Delfs, M. Tows, H.-J. Schmid, Additive Manufacturing, 12 (2016) 314-320.

18. R. Huang, N. Dai, D. Li, X. Cheng, H. Liu, D. Sun, Proceedings of the Institution of Mechanical Engineers, Part C: Journal of Mechanical Engineering Science, 232 (2018) 3384-3395.

19. M. Langelaar, Structural and Multidisciplinary Optimization, 57 (2018) 1985-2004

20. G. Moroni, W.P. Syam, S. Petrò, Procedia Cirp, 36 (2015) 217-222.

21. S. Pereira, A.I.F. Vaz, L.N. Vicente, The International Journal of Advanced Manufacturing Technology, 98 (2018) 1685-1694.

22. Y. Zhang, A. Bernard, R. Harik, K. Karunakaran, Journal of Intelligent Manufacturing, 28 (2017) 1393-1407.

23. M. Biedermann, M. Meboldt, Additive Manufacturing, (2020) 101231.

24. B.P. Heller, D.E. Smith, D.A. Jack, Additive Manufacturing, 12 (2016) 252-264.

25. V. Nienhaus, K. Smith, D. Spiehl, E. Doersam, Additive Manufacturing, 28 (2019) 711-718.

26. N. Guo, M.C. Leu, Frontiers of Mechanical Engineering, 8 (2013) 215-243.

27. J. Suwanprateeb, F. Thammarakcharoen, K. Wasoontararat, W. Suvannapruk, Rapid Prototyping Journal, (2012).

28. R. Paul, S. Anand, Journal of Manufacturing Systems, 31 (2012) 429437.
29. P. Kumar, I. Ahuja, R. Singh, International Journal of Materials Engineering Innovation, 3 (2012) 204-227.

30. D.-Y. Chang, B.-H. Huang, The International Journal of Advanced Manufacturing Technology, 53 (2011) 1027-1037.

31. T. Brajlih, B. Valentan, J. Balic, I. Drstvensek, Rapid prototyping journal, (2011).

32. M. Nikzad, S. Masood, I. Sbarski, Materials \& Design, 32 (2011) 3448-3456.

33. N.S.A. Bakar, M.R. Alkahari, H. Boejang, Journal of Zhejiang University-Science A, 11 (2010) 972-977.

34. L.M. Galantucci, F. Lavecchia, G. Percoco, CIRP annals, 58 (2009) 189-192.

\section{AUTHOR PROFILE}

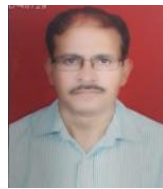

Santosh Kumar Patel, Lecturer, Department of Mechanical engineering, S.V. government Polytechnic college, Bhopal

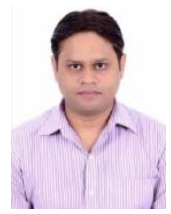

Dinesh Kumar Soni, Assistant Professor, Department of Mechanical engineering, Rabindranath Tagore University (formerly known as AISECT University), Bhopal.

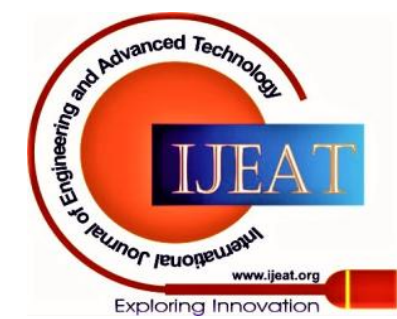

